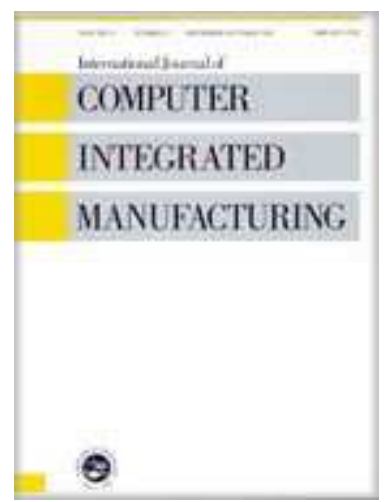

\title{
Power assessment as a high-level partner selection criterion for new product development projects
}

\begin{tabular}{|r|l|}
\hline Journal: & International Journal of Computer Integrated Manufacturing \\
\hline Manuscript ID: & TCIM-2010-IJCIM-0097.R2 \\
\hline Manuscript Type: & Original Manuscript \\
\hline Author: & 06-Jan-2011 \\
\hline Kumplete List of Authors: & $\begin{array}{l}\text { Zolghadri, Marc; IMS-Bordeaux Labs } \\
\text { Amrani, Aicha; IMS-Bordeaux Labs, LAPS } \\
\text { Zouggar, Salah; IMS-Bordeaux Labs, LAPS } \\
\text { Girard, Philippe; IMS-Bordeaux Labs, LAPS }\end{array}$ \\
\hline Keywords: & $\begin{array}{l}\text { SUPPLY CHAIN MANAGEMENT, SUPPLIER SELECTION, PRODUCT } \\
\text { DEVELOPMENT }\end{array}$ \\
\hline Keywords (user): & power assessment \\
\hline
\end{tabular}

\section{SCHOLARONE" Manuscripts}




\title{
Power assessment as a high-level partner selection criterion for new product development projects
}

\begin{abstract}
In New Product Development (NPD) projects, various partners may be involved at different phases and their participation can lead to either success or failure of the project. Therefore, a company that launches a NPD project has to carefully select the most appropriate partners. Currently, partner selection in supply chains is often performed according to well-known criteria such as cost, delay and quality. However, problems could emerge in such processes due to the unavoidable power disequilibrium of the parties involved. The strongest party will sooner or later force the weaker ones to accept more challenging constraints. The use and abuse of power will lead to doubtless mistrust and frustration. Therefore, the awareness of the suppliers' power before any collaboration is of upmost importance and in realistic situations it should be used as a high-level selection criterion.

This paper argues that the power of partners represents a significant issue for the achievement of a coherent supplier selection strategy. An innovative method is suggested to assess the power of each potential partner based on its performances. The joint use of a power-based selection approach and a performance-based selection approach is illustrated at the end of the paper. This study demonstrates how the power consideration can help decision-makers in selecting more relevant partners.
\end{abstract}

Keywords: power, new product development project, partner selection

\section{Introduction}

New product development (NPD) constitutes a key strategy to keep a competitive advantage in the current economic context, which is characterized by increasing customer requirements. Possible improvements for NPD projects were discussed in various works. Some of them underline web applications (Huang and Mak,2001) for supporting product design processes or internet-based collaboration (Nidamarthi et al., 2001). More recently Aldanondo et al. in (Aldanondo et al. 2008) deal with preliminary design through constraint satisfaction problem solving. The authors suggest constraint filtering techniques to provide interactive assistance to designers. These approaches focus on technological improvement of NPD projects while network considerations could guarantee the success of these projects in another way. To improve quality and cost and to reduce the NPD project lead-time, the focal company (FC) that launches the 
product development project seeks adequate partners to involve in the NPD. To perform such projects, the FC often adopts the co-development strategy (Emsden et al, 2006), so the suppliers are involved early to increase the overall performance of the NPD project. Both the Harvard Auto Industry project and later on the International Motor Vehicle Program have mentioned the success of such supplier involvement in the car industry, mainly in Japan (Bidault, 1998). Bidault concluded that buyer-supplier relationships have evolved in Japan from adversarial (in the early 1960s) to cooperative management with equity links, technology transfer and managerial assistance. Thus, as a pioneering sector, the car industry showed that subcontracting with suppliers should be a real business strategy going far beyond looking at suppliers as capacity buffers. This lead to a new scientific branch called Early Supplier Involvement (ESI).

According to Dowlatshahi in (Dowlatshahi,1998) ESI concerns "the integration of the capabilities that suppliers can contribute to NPD projects". In (Van Echetlet et al., 2008) authors perceive ESI as a more sophisticated concept underlining the responsibility of suppliers: "the suppliers are expected to carry out tasks required by the customer, and they assume even the responsibility for the development of a part, process or service".

Many authors believe that implementation of ESI has lead to better performance due to the following factors: successful innovation (Rothwell et al., 1974, Womack et al. 1991, Imai et al. 1986, Clark and Fujimoto, 1991), better use of suppliers' technological competence (Slade, 1993), reduced costs and time to market and improved quality and productivity, speed (Womack et al. 1991, Imai et al., 1986, Clark and Fujimoto, 1991, Kamath and Liker 1994, Ragatz et al., 2002, Song and Beneditto, 2008), improved design for manufacturing (Wasti and Liker, 1997) and decreasing risk of design-related delay (Hartley et al, 1997).

These improvements were discussed from the point of view of the customer. The positive effects have also been described for suppliers (Heide and John, 1990 cited in Labahn, 2000). Reducing inventories along with lower administrative, sales and overhead costs (Kalwani and Narandas, 1995) are other factors that lead suppliers to ESI.

Nevertheless, ESI is not exclusively advantageous. Based on a survey, Johnsen in (Johnsen, 2009) demonstrates that there are serious concerns about the real benefits of ESI in NPD projects. He analyses the research performed over three decades. Many researchers have considered the positive effect of supplier involvement on product 
development performance (Cusomano and Takeishi, 1991; Lamming, 1993; Kamath and Liker, 1994) while others observe less positive effects of ESI (Eisenhardt and Tabrizi, 1995). Wasti and Liker in (Wasti and Liker, 1997) identified a positive effect of ESI when technological uncertainties exist, while Swink showed that the product newness could be less positive for ESI, see (Swink,1999). The long-term alliances between firms were also considered as innovation leverage, but Primo and Amundson in (Primo and Amundson, 2002) note that alliances could alter innovation possibilities in the supply chain. Table 1 summarizes potential benefits and risks that a customer or a supplier may see when participating in an ESI relationship.

\section{< Please insert Table 1 approximately here.>}

Subsequent to these reported works suggesting that ESI has some critical issues (Bidault et al., 1998; Wasti, 1997; Swink, 1999; Hartley, 1997; Johnsen, 2009), the large push of academics towards the ESI in the 1980's and 1990's has become more moderated.

In this respect, some authors revealed that the suppliers must be selected according to more realistic criteria (Wasti and Liker 1997, Hartley et al, 1997, Peterson et al 2005, Koufteros et al 2007, Song and Benedetto 2008, LaBahn, 2000 and Johnsen 2009). Perterson et al. in (Perterson et al., 2005) go beyond the supplier's efficiency and recommend evaluation of suppliers by the customer in terms of complementarities of capabilities and culture.

Somehow, suppliers' involvement failed in some NPD projects due to dysfunctions during their collaboration for some unanticipated reasons. Misunderstanding, distrust, frustrations or even more complicated situations (judiciaries issues) emerged among collaborators due to the use or abuse of power by stronger parties.

It is therefore necessary to improve the supplier selection process taking account of higher level selection criteria or long-term possibilities for instance. Selecting the most relevant potential partner means more than selecting the most performer one. The FC could think of long time collaboration leading finally to win-win relationships despite the immediate low-level performances of a potential partner. This leads to supplier development. In (Sanchez-Rodriguez et al.,1996) and (Hartley and Jones, 1997) authors focused on supplier development practices and revealed how supplier development activities could help FC to increase its purchasing performance. Recently (Abdullah et 
al.,2008) show that firms need to evolve from traditional to strategic purchasing through standardization of components and to do so the firms' attitudes should change from confrontation to trust and partnership.

In our research, we focus on the power of partners and more precisely the power imbalances that influence the partnership. Indeed the power advantage can be destructive if the more powerful party is prone to exploit the weaker one.

This paper argues that the power of partners has to be assessed and analysed as clearly as possible far in advance in order to guarantee a win-win collaboration or at least to offer companies a clearer view of their respective power. Our research aims to provide a methodology for this analysis. The article is structured as follows. The literature review in section 2 analyses two points: partner selection and power in supply chains. This section discusses previous works and justifies our contribution. Section 3 discusses necessary concepts gathered in a power-based partner selection approach. This section shows how the performance metrics can be transformed into power inducers. These power inducers are then aggregated by a method, which borrows some of its components from the AHP invented by Saaty. The purpose of this method is to illustrate the feasibility of the power-based partner selection approach. The mathematical issues are not the main focus of this paper. Possible improvements of the aggregation techniques will be discussed in the last section of the article. The proposed approach is then applied to an illustrative case designed by our research team. After the selection of some performance metrics, the power-based approach is applied to this case and the results are compared to those obtained by a pure performance-based AHP approach. By analyzing these results, it is possible to highlight their complementarity. Finally, a concluding discussion and some perspectives are at the end of the paper.

\section{Review of partners selection criteria and power assessment}

\subsection{Partners selection}

The criteria for partner selection have been discussed in many studies, the selection of partners being a key success factor for companies in the past years (Lau and Wang, 2002). Finding the relevant selection criteria and developing an appropriate partner 
selection model is gradually becoming the most important issues to consider before any alliance formation ( $\mathrm{Wu}, 2009$ ) because the resulting partners can profoundly impact the financial and operational health of the company. This impact is even deeper if the partners contribute not only to the realisation of the target product but also to its design.

In one of the earliest works in this field, Dickson found that quality and delivery delay were some of the most important selection criteria, see (Dickson, 1966). Weber in (Weber,1991) suggested a classification of selection criteria and found that price, delivery, quality, production capacity and the geographical position were the most used selection criteria.

Some authors saw the necessity of structuring selection criteria, and they began to think of a wide criteria system to guide decision makers in choosing partners according to their industrial, technical and environmental context. Geringer puts forward a distinction between task-related selection criteria (associated with strategic resources and skills) and partner-related selection criteria (associated with measurement of how partners can effectively work together), see (Geringer, 1991). Barabarosoglu and Yazgac propose a hierarchical structure of criteria summarizing the supplier's characteristics: performance assessment, business structure/manufacturing capability assessment and quality system assessment, in (Barabarosoglu and Yazgac, 1997). (Huang and Keskar, 2007) put the selection criteria into three categories: product related, supplier related and society related. The product-related criteria are structured into reliability, responsiveness, and flexibility metrics. Cost and financial, and assets and infrastructure categories are the subclasses of the supplier-related category. Finally, safety and environmental criteria belong to the society-related category.

Araz and Ozkarahan pointed out though that the traditional selection criteria (cost, quality and delivery) are not enough for strategic supplier selection and they suggested other criteria such as quality management practices, long-term management practices, financial strength, technology, innovativeness, cooperative attitude of the supplier, and co-design and cost-reduction capabilities of the supplier (Araz and Ozkarahan, 2007). However, the partner selection theory still needs more research to make it relevant to managers' needs (Chung, Singh, \& Lee, 2000; Hitt et al., 2000) mainly in terms of environmental (power of firms) and social (reputation, position in the market,...) 
aspects (Wu et al, 2009). Recently authors in (Feng et al, 2010) address this question by studying the partner selection process through "individual" or "collaboration" utility. The authors argue that the individual utility considers a single candidate partner (performance criteria) while the collaboration utility deals with relationships among involved partners. In other words, the collaboration utility underlines the fact that a partner should have not only good intrinsic performance (individually) but also good interactions with others in the supply chain. This is related to the system theory in which a single component cannot be studied without the entire system to which it belongs and the interactions it has with other components, see (von Barthelanfy, 1976). This systemic view is a fundamental axiom adopted in this paper.

\subsection{Consideration of partners power in management and social sciences}

In a company that looks for selecting partners for realisation and/or development, some modules have to be aware of the collaborative situation that could rise from a potential imbalance of power. As Thenbrunsel et al. say in (Thenbrunsel et al.,1997) , "one factor that impacts the partnership is the power of negotiators".

The concept of power became popular in the engineering fields when Porter presented his Five Force model, (Porter,1980) . Power represents an important factor behind the supply chain development and deployment according to (Crook and Combs, 2007); the power of partners is an unavoidable reality that influences the collaborative relationships. Power enables stronger firms to gain favourable exchange terms from others, or more broadly, to coerce others to do what they would not otherwise do, cf. (Emerson,1962) and (Pfeffer,1981).

Gaski in (Gaski,1984) reports on the concept of power defined by Cartwright (1959) "When an agent $O$ performs an act resulting in some change in another agent $P$, we say that $O$ influences $P$. If $O$ has the capability to influence $P$, we say that $O$ has power over P". The research reported here is based on the definition of power suggested by Martin as the "success of one group in obtaining compliance with its wishes regardless of the opposition of others", see (Martin, 1992). His studies of power focus mainly on the socalled zero-sum model of power between two parties, in which an increase of power of 
party $A$ inevitably involves a reduction of power of party $B$. This reflects the assumption that in a given situation "there is a fixed amount of power, which is indivisible".

Emerson in (Emerson,1962) defines power as an inherent property of the relation; it is not an attribute of the actor, which underlines the systemic view of the power as mentioned in the last section. Emerson links two concepts: Power and dependency. He defines the power of $A$ over $B$ as a consequence of the dependency of $B$ to $A$ : "The power of $A$ is the amount of resistance on the part of $B$ which can be potentially overcome by $A$. The dependence of actor $B$ upon actor $A$ is (1) directly proportional to $B$ 's motivational investment in goals mediated by $A$, and (2) inversely proportional to the availability of those goals to $B$ outside of the $A-B$ relation".

The fundamental axiom claimed by Emerson is that an imbalanced relation is unstable, and he studied processes that tend to reduce this imbalance. These processes are called cost reduction and balancing operations. Cost reduction refers to all activities that target a minimisation of the "cost" involved for one party in meeting the demands of the other. This mainly refers to the consensus that the weaker party accepts because it looks for attaining the goals. Balancing operations aims at acting on motivation and attainability of goals through four possible actions to balance the power between $A$ and $B$ by "(1) the reduction of B's motivational investments in goals mediated by $A$, (2) cultivating $B$ 's alternative sources for gratification of those goals, (3) increasing A's motivational investment in goals mediated by $B$, and (4) denying $A$ 's alternative sources for achieving those goals".

This concept of mediation is due to (French and Raven,1959), largely cited in the scientific literature, who distinguish mediated from non-mediated power, in (Zhao et al.,2008) and (Flynn et al.,2008). The mediated power expresses the power controlled by the customer on the supplier (which can reward or coerce a manufacturer). In contrast, non-mediated power represents the perception of the customer's power by the supplier. The supplier itself decides whether and how much it will be influenced by a customer (perception of expert power, referent power and legitimate power). Often, the customer may not even be aware that these powers exist.

Much of the literature about power asserts that a power advantage is destructive, because a more powerful party tends to exploit its advantage (McAlister, et al, 1986 and Pruitt, 1981). Lawler in (Lawler,1992) states that an imbalance of power fosters the use of hostile rather than conciliatory tactics. LaBahn and Krapfel note that the power 
dynamics within buyer-supplier relationships should not be underestimated, see (LaBahn and Krapfel, 2000). They affirm that "powerful customers, who abuse their power advantage and behave opportunistically, may ruin the trust that is a critical ingredient in supplier involvement projects". It can be concluded that powerful suppliers in product development projects may threaten the collaborative relationships with the company. In choosing partners it is then advised to pay attention to the power of suppliers and, more generally, to all partners.

Although power has been studied largely in the aforementioned works, a great lack of understanding still exists in power assessment. It is remarkable to see that many theories exist about the effect of the power on a bilateral relationship but, as far as we have found, the issue of power assessment has rarely been addressed in engineering fields except in (Cho and Chu,1994). These authors use the basic concepts of Porter's Five Force framework (Porter,1980) distinguishing intrinsic bargaining power and managers' propensity to exert it. They postulate that intrinsic bargaining power comes from structural variables that constitute the whole industry, called industry-specific. Propensity to exert power is influenced by variables related to situations that a specific firm faces, called firm-specific. In this model, the bargaining power of each partner is the product of the intrinsic bargaining power and the factors influencing the party's propensity to exert this power. This method was applied by the authors to an industrial case from the shoes industry.

\subsection{Positioning of our contribution}

From this state of the art, it is outstanding to notice that rarely the question of power is considered in selection processes in the engineering-related literature, and power assessment techniques are rarely suggested. The methodology proposed in this article is an attempt to assess the power of each potential partner to influence the power imbalance or at least to generate an awareness of it for actors. A supplier could better reject an order of a stronger customer, or a customer can look for a weaker supplier. In short, the basic axioms of our research are as follows: 
- Relations instead of individuals, a systemic view. The main selection criteria in existing methods, referred here as performance-based selection approaches, are associated with partners. A performance indicator informs us about a partner, for instance notifying us that its delivery delay is 3 weeks.

Such a performance indicator is an inherent attribute of a partner.

In this case, the partner is considered in an isolated manner without any relation to other actors. The focus of the performance-based selection approaches is then on individuals and their performances. These approaches compare potential partners together by comparing their performance indicators (price, delay, etc.).

The research reported here switches its focus from individuals to relations. These relations exist between those potential partners and the focal company. Therefore, it transforms performance indicators into power inducers. A power inducer is an inherent property of the relation linking a potential partner to the focal company.

The transformation principle consists in determining the focal company will by obtaining the collaboration of the potential partner according to its own goals and context (strategy, market, etc.). To do so, the focal company should judge whether the performance metric value (the 3 weeks of delivery delay for instance) of the potential partner is interesting enough or not according to its goals. This is somehow the "price" that the focal company is ready to pay to benefit from the performance of that potential partner (the attribute of the partnership among two actors). One given performance value can be judged very interesting by a customer in some situations while in another case, (s)he does not find it relevant (Figure 1).

\section{< Please insert Figure 1 approximately here.>}

- Relative power assessment. Measurement is a process that defines the magnitude of a quantity (the delay for instance) referring to a unit of measurement. However, as there is no way to measure the power of a company, in the proposed approach in this paper, the target is to compare the assessed relative power of companies. The result is to obtain an order among them expressed by stronger than or weaker than or equals to. 
- $\quad$ Power is multi-dimensional. Power is made of a lot of dimensions. Some are linked to the market situation while others are related to the company. Authors restrict intentionally their research presented here only to those dimensions connected to the performance of the companies. Other aspects are not considered here. The purpose of the approach is to allow analysts to use this power assessment as a diagnosis tool.

\section{Power-based partner selection approach}

To describe the so-called power-based partner selection approach, the following conventions are adopted:

FC: Focal Company willing to select partners for a NPD project

$P_{k}$ : Potential Partner $k$ of the $F C$

$\left(F C, P_{k}\right)$ : Business relationship of $F C$ with $P_{k}, k \in\{1, . ., n\}$

$c_{i}, i \in\{1, . ., m\}$ Aggregated performance criterion (i.e. cost, delays, quality, fill rate,...)

$c_{i j}, j \in\{1, . ., S\}$ Detailed performance criterion $j$ of the aggregated criterion $i$

We suggest studying the partnership $\left(F C, P_{k}\right)$ of $F C$ with a potential partner $P_{k}$ related to one performance criterion $c_{i}$. This will noted $\left(F C, P_{k}<c_{i}>\right)$.

\subsection{Overall approach}

Commonly, performance-based partner selection approaches rank potential partners based on their performance. Techniques (such as AHP) allow analysts to solve such ranking problems. Figure 2 presents the main differences between performance-based and power-based partners selection approaches.

< Please insert Figure 2 approximately here.>

\subsection{Concept of power $\pi\left(F C, P_{k j}<c_{i}>\right)$}

A given business relationship $\left(F C, P_{k}\right)$ with a partner $P_{k}$ exists if and only if $F C$ and $P_{k}$ are dependent, Emerson(1962). This means that $P_{k}$ has a resource that $F C$ needs. This business relationship, generated due to that resource dependency, can be characterized by several performance criteria $c_{i}$ (i.e. brand image of the partner, cost and delay of the 
delivered items, after-sale services proposed by the partner, the mastered technology, ...). Each criterion $c_{i}$ can be evaluated by one or several detailed performance criteria if necessary. In this case, it can be written that $c_{i}=\left\{c_{i 1, . .,} c_{i j j . . .}\right\}$. For instance, the cost can be the aggregation of two performance measures: the cost per unit of a supplied item and the cost of after-sale service.

Let us study the partnership described only by one of its performance criterion $\left(F C, P_{k}<C_{i}>\right)$. The $F C^{\prime}$ s managers are asked to judge their will in obtaining the collaboration of this partner knowing the value of that performance metric. This corresponds to a supply and demand law because it defines the will of a demander to obtain something from a supplier. In other words, a performance value, which is an attribute of the potential supplier and $P_{k}$, is transformed to an attribute of the relationship that could be established between the $F C$ and $P_{k}$. This is the core idea of the approach introduced here.

The judgment of the managers will be expressed by a power inducer, which is an image of that performance metric $\left\langle c_{i}>\right.$. The power inducer can be notated $\pi\left(F C, P_{k}<c_{i}>\right)$ or more easily by $\pi_{k, i j}$.

This idea is illustrated through a simple example: A customer A needs a tool that a supplier B can provide (i.e. A depends on B). The customer A will judge this possible partnership based on several metrics, among others the cost of the after-sale service asked by B. If this price is highly competitive, A's desire to obtain this partnership will be very high. A is thus ready to make concessions in order to obtain the co-operation of $B$, and this will generate a power relation between them. In this case, and regarding the cost of the after-sale service, intuitively one can deduce that $A$ is weaker than $B$.

After sale service cost could be one of the components of an aggregated criterion. In this case, an aggregation should be applied to transform $\pi_{k, i j}$ to $\pi_{k, i}$. Obviously, the power of $A$ and $B$ is not only based on the after-sale service. The $A-B$ relationship should also be considered according to other performance metrics. This will provide various power inducers that must be then aggregated into one final value that represents the relative power of the two parties, $A$ and $B$.

As a general remark, the transformation of performance measures into power inducers is necessary because the performance measures are heterogeneous (cost, delay, willingness, ...) and incomparable, i.e. there is no way to directly combine them. Thus, 
they should be transformed into homogenous metrics. The threshold technique, introduced in next section accomplishes this transformation.

Before discussing the threshold technique in detail, let us describe the possible values of the power of a relationship regarding a criterion and each performance measure of a potential partner. It is proposed here that the power inducer can have three possible values describing three different situations:

1- Partner $P_{k}$ is stronger than FC corresponds to two joint conditions:

- $\quad$ FC and $P_{k}$ are dependent.

and

- The performance of this potential relationship may result in a good chance of success for the $F C$.

Or

- $\quad$ FC is more interested in this relationship than that potential partners is.

The $F C$ is ready to negotiate and to accept some of the partner's requests in order to obtain this partnership. We note this situation by " $P_{k}+$ ". For instance, this could be the case for a very low price of a supplied component or its very high quality offered by the supplier.

2- FC is stronger than $P_{k}$. corresponds to the situation where the following conditions are satisfied:

- $\quad F C$ and $P_{k}$ are dependent.

and

- $\quad$ The $F C$ is aware of the fact that its collaboration with this potential supplier could result in a better chance of success for the partner.

or

- $\quad$ FC is less interested in this relationship than that potential partners is.

The FC is stronger than the partner, even if the $F C^{\prime} s$ need remains. We note this situation "FC+".

3- FC and partner $P_{k}$ are balanced. Two conditions describe this situation: 
- $\quad F C$ and $P_{k}$ are dependent.

and

- $\quad$ Regarding the considered performance, the relationship presents same level of opportunities and/or risks for both the $F C$ and the partner.

Thus, the $F C$ and partner forces are balanced. This situation is notated by "=".

\subsection{The threshold technique}

The thresholds technique transforms heterogeneous criteria values into homogenous power inducers. It consists of determining the two thresholds, $T_{1}$ and $T_{2}$ by the $F C$ managers for every selection criteria (Figure 2). The basic action of the threshold technique can be written as follows:

$$
\left\{\begin{array}{l}
\left(F C, P_{k},<c_{i}>\right) \stackrel{\text { thresholds }}{\longrightarrow} \pi_{k, i} \\
\left(F C, P_{k},<c_{i j}>\right) \stackrel{\text { thresholds }}{\longrightarrow} \pi_{k, i j}
\end{array}\right.
$$

These thresholds allow three possible power situations:

- $\quad$ Rule-1.

" $F C+$ " (i.e. $F C$ is stronger) is declared for values belonging to [ $T_{2}$,Limit Value], (the partner's performance value is worse than T2).

- $\quad$ Rule-2.

" $P_{k}+$ " (i.e. partner is stronger) for values belonging to [Limit Value, $T_{1}$ ], and (the partner's performance value is better than $\mathrm{T} 1$ )

- $\quad$ Rule-3.

"=" (i.e. balanced power) for values belonging to the interval $\left[T_{1}, T_{2}\right]$.

The determination of thresholds and the necessary analysis can be done by the $F C^{\prime} S$ experts. For instance, the return velocity and fill rate thresholds can be provided by the quality department.

By considering the examples in Figure 3, it is seen that two situations are possible in the determination of the power inducer. In example 1 , the $F C$ is stronger when the measured performance is as big as possible. This is the case of delivery cycle time. If the partner has a very long delivery cycle time, longer than a determined threshold $T_{2}$, then the $F C$ can be judged as stronger than the partner because of the bad performance of the partner. This corresponds to $F C+$. In example 2, the $F C$ is stronger when the measured performance is as small as possible, such as fill rate. If a partner has a bad fill rate, less 
than threshold $T_{1}$, then the $F C$ is stronger. In short, the $F C$ is stronger when the performance of the partner is low (high delivery lead time or small fill rate).

\section{< Please insert Figure 3 approximately here.>}

\subsection{Assessment of power}

The power inducers $\pi_{k, i j}$ and $\pi_{k, i}$ are then aggregated step by step into $\pi_{k, i}$ and $\pi_{k}$ to assess the power of the FC and its potential partner. This means the following:

$$
\left\{\begin{array}{c}
\pi_{k, i j}, \forall j \stackrel{\text { aggreg }}{\longrightarrow} \pi_{k, i} \\
\pi_{k, i}, \forall i \stackrel{\text { aggreg }}{\longrightarrow} \pi_{k}
\end{array}\right.
$$

Various aggregation methods can be applied to determine the power knowing power inducers. This aggregation will be done either in literal or in numerical ways. The literal analysis technique should manipulate literal values such as $F C+, P_{k}+$ or $=$, while in the numerical technique, a numeric value is associated with each of these three possible balance situations: " 0 " corresponds to a balanced situation, " +1 " to $F C+$ and "- 1 " to $P_{k}+$ allowing further calculations. We will use the numerical valuation to calculate the power of partners hereafter.

In section $\S 3.1$, it was considered that the aggregated criterion $c_{i}$ may be composed of detailed criteria $c_{i}=\left\{c_{i 1}, . ., c_{i j}, ..\right\}$. Let $\alpha_{i j}$ be the weights of detailed criteria $c_{i j}$, and $\beta_{i}$ the weights of sets of aggregated criteria of $c_{i}$. In this case, the relative power of a potential partner is calculated according to the following formulae:

$$
\left\{\begin{array}{l}
\pi_{k, i j}, \forall j \stackrel{\text { agg. }}{\longrightarrow} \pi_{k, i}: \pi\left(F C, P_{k},<C_{i}>\right)=\sum_{j=1}^{s}\left(\alpha_{i j} \cdot \pi_{k, i j}\right) \\
\pi_{k, i}, \forall i \stackrel{\text { agg. }}{\longrightarrow} \pi_{k}: \pi\left(F C, P_{k},<C>\right)=\sum_{i=1}^{m} \beta_{i} \cdot \pi_{k, i}=\sum_{i=1}^{m} \beta_{i}\left[\sum_{j=1}^{s}\left(\alpha_{i j} \cdot \pi_{k, i j}\right)\right]
\end{array}\right.
$$

These are the weighted sums where weights $\alpha_{i j}$ and $\beta_{i}$ represent the importance of one criterion over others. The determination of these weights must be assessed based on the application. In our first application presented here, we decided to use Saaty's AHP preference scale and techniques to calculate these weights (see Table 2) because they take account users' preferences and can be obtained by audits. Interested readers should refer to (Saaty ,2005) for a detailed description of the technique. 
< Please insert Table 2 approximately here.>

As a reminder, hereafter the calculation of $\alpha_{i j}$ and $\beta_{i}$ is detailed. The AHP principle for weight calculation compares criteria pairwise by using the preference values defined by Saaty (see Table 4).

Let $Q_{\pi}$ be the matrix of these pairwise preferences. In this case the possible matrices are $Q\left(\pi_{k, i j}\right)=\left[q_{l r}\right]_{s^{*} s}$ and $Q\left(\pi_{k, i}\right)=\left[q_{I r}\right]_{m^{*} m}$ where $s$ and $m$ are the number of considered criteria (detailed and aggregated). The value of $q_{l r}$ represents the preference of the criterion $l$ over the criterion $r$. The possible values of $q_{l r}$ are $\{1,2, . ., 9\}$ representing Saaty's preference scale (see Table 4). Thus, $q_{32}=3$ means that criterion 3 has a "moderate importance" relative to criterion 2 . The whole preference table is identified, step by step, by comparing criteria pairwise knowing that $q_{l r}=q_{l r^{-1}}$ and $q_{l l=1}$.

Finally $\alpha_{i j}$ and $\beta_{i}$ are obtained by the following formulas.

$$
\alpha_{i j}=\frac{\left[\prod_{r=1}^{s} q_{l r}\right]^{\frac{1}{s}}}{\sum_{l=1}^{s}\left[\prod_{r=1}^{s} q_{l r}\right]^{\frac{1}{s}}}
$$

$$
\beta_{i}=\frac{\left[\prod_{r=1}^{m} q_{l r}\right]^{\frac{1}{m}}}{\sum_{l=1}^{m}\left[\prod_{r=1}^{m} q_{l r}\right]^{\frac{1}{n}}}
$$

The use of the AHP technique for weights calculation provides the power values such as $\pi\left(F C, P_{k}\right)=\pi_{k} \in[-1,1]$.

\subsection{Algorithm of power assessment}

Here we present the algorithm used by the focal company for ranking partners according to the power values.

Let:

- $\Omega=\left\{P_{1, . .,} P_{k_{2} . .} P_{n}\right\}$ be a set of potential partners,

- $\Psi=\left\{c_{1}, . . . c_{i, . . .} c_{m}\right\}$ be a set of aggregated criteria,

- $\quad \zeta=\left\{c_{i 1, . .,} c_{i j, . .,} c_{i s}\right\}$ be a set of detailed criteria

For each $P_{k} \in \Omega$

For each $c_{i} \in \Psi$

Step 1: Calculate power inducer $\pi_{k}$, and $\pi_{k, i j}$ of partner $P_{k}$ regarding the criteria $c_{i}$ and $c_{i j}$ 
For every $c_{i}, \forall i$

Let $\mathrm{L}_{\min (\mathrm{i})}, \mathrm{L}_{\max (\mathrm{i})}$ be the minimum and maximum limits values of $c_{i}$, respectively Let $T_{i 1}$ and $T_{i 2}$ be two thresholds fixed by experts:

$$
\pi_{k, i}=\left\{\begin{array}{r}
+1 \text { if } T_{i 2} \leq c_{i} \leq L_{\max (i)} \\
0 \text { if } T_{i 1} \leq c_{i} \leq T_{i 2} \\
-1 \text { if } L_{\min (i)} \leq c_{i} \leq T_{i 1}
\end{array}\right.
$$

If $c_{i}$ is composed of detailed criteria $c_{i j}$

Then

$$
\text { For every } c_{i j}, \forall j
$$

Let $\mathrm{L}_{\min (\mathrm{ij})}, \mathrm{L}_{\max (\mathrm{ij})}$ be the minimum and maximum limits values of $c_{i j}$, respectively

Let $T_{i j, 1}$ and $T_{i j, 2}$ be two thresholds fixed by experts:

$$
\pi_{k, i j}=\left\{\begin{array}{c}
+1 \text { if } T_{i j, 2} \leq c_{i j} \leq L_{\max (i j)} \\
0 \text { if } T_{i j, 1} \leq c_{i j} \leq T_{i j, 2} \\
-1 \text { if } L_{\min (i j)} \leq c_{i j} \leq T_{i j, 1}
\end{array}\right.
$$

Step 2: Calculate the weights for each criterion

For each $c_{i}, \forall i$

Calculate the weights of aggregated criteria $\beta_{i}$ using formulae (3)

For each $c_{i j}, \forall j$

Calculate the weights of detailed criteria $\alpha_{i j}$ using formulae (2)

Step 3: Calculate the power

Using the formulae (1) calculate the power $\pi\left(F C, P_{k}\right)=\pi_{k} \in[-1,1]$.

\section{Illustration and analysis}

In this section, the power-based selection approach is applied to a case study, designed in our laboratory to illustrate the capability of the proposed approach.

A possible way to extend the use of bicycles is to transform basic bicycles into electrical power-aided ones by assembling electrical power-assist kits. This solution (basic bicycle + power-assist kit) is cheaper (\#400€-600€) than electrical power-assist bicycles sold by manufacturers (\#1000€-1500€). Therefore, it is reasonable to assume that a large customer can launch a call for tenders in order to improve its existing bicycles into power-assisted ones. 
A typical call for tenders for such kits could contain the following elements:

- Technical specification of existing bicycles. Male and Female bicycles with 7 gears.

- Cost constraints. The total price must be less than $100 € /$ kit (motor and battery).

- Delay. The delay for preparing 100 bicycles should be less than 1 week.

- Quantity. The project could concern 4000 bicycles (typical for a big town).

- Battery autonomy. $30 \mathrm{~km}$ for a total weight of $100 \mathrm{~kg}$.

- Battery weight. Less than $7 \mathrm{~kg}$.

- Charge duration. Maximum 4 hours.

- Motor module weight. Less than $3 \mathrm{~kg}$.

- Aesthetics. Should be included in an aerodynamic box that is easily assembled to the bicycle body.

A bicycle manufacturer, called Centaur Bicycle, could answer such a call for tenders. Centaur Bicycle can either choose to design and manufacture all of the necessary modules or in a more realistic situation it could require help from some suppliers. These suppliers should design and manufacture the modules asked by Centaur Bicycle. For traditional manufacturers such as Centaur Bicycle it is quite reasonable to hypothesize that they are able to design and manufacture mechanical devices necessary to assembly the motor to the bicycle while sourcing batteries and the motor-assistance module. In this case, Centaur Bicycle should determine its best supplier(s) for providing the motorassistance module in an engineered-to-order way.

Let say that Centaur Bicycle has prepared a short list of five potential suppliers of motor-assistance modules using its business intelligence. These partners are labelled $P_{1}$, $P_{2}, P_{3}, P_{4}$ and $P_{5}$.

\subsection{Application of the power-based partner selection approach}

A collection of selection criteria was presented to the members of our research team in order to choose some of the most relevant criteria that could be used in such a situation. The final list of criteria and their variation domain (boolean, real, a list of possibilities, etc. ), the associated thresholds, and the corresponding power inducers are presented in Table 3. Readers should keep in mind that only the thresholds are new in this assessment methodology while all performance metrics value and their related domains 
are known even for any performance-based selection approach. The power inducers are obtained simply once the thresholds are suggested by users.

The elementary criteria were grouped into aggregated criteria as follows: $A=\left(a_{1}, a_{3}\right)$, $B=\left(b_{2}, b_{3}\right), C=\left(c_{2}, c_{9}\right), D=\left(d_{2}, d_{4}\right), E=\left(e_{1}, e_{2}, e_{3}\right), F=\left(f_{1}, f_{2}\right), G=\left(g_{1}, g_{3}\right), H=\left(h_{5}, h_{8}\right), I=\left(i_{4}, i_{5}\right), J=\left(j_{5}, j_{8}\right.$, $\left.j_{15}\right)$.

< Please insert Table 3 approximately here.>

Then, for every aggregated criterion its detailed criteria were judged pairwise according to the AHP preference scale. The same approach was applied to the aggregated criteria $A, B, . ., J$ which were compared pair wise. This allows the calculation of the weights of aggregated and detailed criteria, $\beta_{i}$ and $\alpha_{i j}$ (see Table 4).

< Please insert Table 4 approximately here.>

\subsection{Application of AHP as the performance-based partner selection approach}

In addition to the power-based selection approach, a performance-based selection approach was applied to this case for comparison. The chosen performance-based approach was the pure AHP method, as shown in Figure 4. Alternatives (the potential partners in the vocabulary of this paper) are assessed against each of the criterion and by using the weights of criteria obtained by using formulas (1) and (2), and the final ranking of suppliers, based on their performances is calculated.

In this application of the AHP approach, we used the geometric mean to achieve the ranking, see (Barzilai,et al., 1987; Budescu, et al., 1986; and Golany, et al., 1993). The results are equal to common eigenvalue calculations often used in the literature. Some of the intermediate results are provided in the appendix of the paper while the final results are shown in the bottom rows of the figure 5.

< Please insert Figure 4 approximately here.> 


\subsection{Analysis of results}

The powers of each potential supplier $P_{1}, \ldots, P_{5}$ are obtained by calculation of power inducers related to each detailed criterion (22 in total) according to formula (1).

The final results of the power-based selection approach are shown in the top rows of Figure 6. It might be concluded that the $F C$ would be dominated by $P_{1}(-0.55)$ while it dominates $P_{3}(+0.13)$. In any case, the power balance does not offer a strong position to $F C$. It can be concluded that the FC will be in more or less balanced power situations towards $P_{2}, P_{3}, P_{4}$ and $P_{5}$ as indicated by power values very close to zero, or in the worst situation, it will be dominated by $P_{1}$.

It is interesting to observe that the ranking of partners obtained by the performancebased approach shows that $P 1$ is more efficient than its competitors $(0,23)$. Therefore without paying attention to the power values, Centaur Bicycle logically chooses $P 1$. However, collaboration problems could occur afterwards due to the power imbalance between Centaur Bicycle and $P 1$ because this partner is stronger than the FC and it can exert its power to obtain better conditions than those that the FC is ready to concede.

\section{< Please insert Figure 5 approximately here.>}

In this example, by analysing the power, collaborating with $P 1, P 2$ or $P 4$ seems to be potentially risky for the $F C$ because of possible domination by these potential partners. Dealing with $P 1$, where the disequilibrium is high, is riskier than dealing with P2 and P4, where the disequilibrium is close to zero. Dealing with partner $P 5$ whose performance $(0.21)$ is almost equal to partner $P 1$, the $F C$ is stronger than $P 5$. The imbalance of power is very low. This partnership with P5 seems promising in terms of performance value and power value, more promising than collaboration with the powerful $P 1$. This partner is efficient and could not easily dominate the $F C$ due to its low-level power imbalance.

Based on these results, it can be seen that the power consideration could lead to the choice of a less performer partner, but with the advantage of ensuring that the power disequilibrium is smaller and minimizing potential conflicts. Therefore the simultaneous consideration of performance metrics and power metrics could give a better insight to partner selection. 


\section{Conclusions and Perspectives}

Partner selection has been studied for many years as a question of the buying department; however, it is clear that further research must be done in this domain. Partners directly influence the success of any NPD project. A necessary partner could be discouraged or a good business partnership may be disrupted by application of an irrelevant selection approach by generating frustration.

The goal of the power-based supplier selection approach described here is to determine the right suppliers, involved at the right time, that offer the right contributions. This article argues that the power can be and should be used as a high-level partner selection criterion because power plays a fundamental role in business (negotiations) and collaboration with partners. In fact, it is mentioned that a strong company may dictate attitudes or activities to weaker ones, losing their trust. This increases industrial risks for the entire project. As far as we have identified, no power measurement methods is suggested in the engineering field except for the article of Cho and $\mathrm{Chu}$, (Cho and Chu, 1984).

The fundamental idea behind the power-based partner selection is to move the focus of the study from individual partners (used in performance-based selection approaches) to the relationship between a demander and a supplier (i.e. between the FC and its supplier). Once this idea is discussed and the necessary concepts introduced, we introduce a power-based selection procedure using the weighted-sum method to rank partners according to their power (domination or subordination). The weights are calculated by using the AHP preference scale. This method was then applied to an experimental case study and compared with a performance-based partner selection approach, designed within our laboratory. The mathematical technique is not the core idea of this approach and the used weighted sum should be improved in the future, for example, by looking at fuzzy aggregation techniques.

Some lessons were learned from the application of this approach to the illustrative cases. First, the use of the approach is reasonably complex, but the quality of results depends directly on the assessed or observed values of selection criteria and also on thresholds. These thresholds and performance or selection criteria are assessed or 
evaluated either subjectively or objectively. In the first case, analysts have an influence on the value (for instance willingness). Therefore, it is important to apply methods which minimise this influence as much as possible. The suggested approach can be extended to other power-oriented criteria, for instance that of Porter in the Five Force model, to take into account more complex partner selection scenarios. Those other dimensions are not considered in this paper. Providing a clear image of power of potential partners could be completed by further developments describing these complementary dimensions manipulated with adequate mathematical techniques.

Power can rise in relationships where more than two actors are involved simultaneously. The analysis complexity is much higher in this case than in bilateral relations where mutual influences and couplings can be discovered. This leads to the consideration of power networks hidden behind these multi-lateral relations. Further research would provide convincing answers to this challenge.

Finally, one of the most interesting works in this area will deal with the sensitivity analysis of threshold uncertainty in order to reduce the influences of the analysts subjectivity.

\section{Acknowledgement}

This research was performed partly by the support of ESTIMATE project (2008-2010), a Eurostars programme funded by the European Community. 


\section{Appendix}

< Please insert Tables of the appendix here.> 


\section{References}

Abdullah R., Lall M.K., and Tatsuo K., 2008. Supplier Development Framework in the Malaysian Automotive Industry: Proton's Experience, Int. Journal of Economics and Management, 2(1), pp: 29 - 58.

Aldanondo M., Vareilles E., Hadj-Hamou K., and Gaborit P., 2008. Aiding Design with Constraints: an Extension of Quad Tree in order to deal with Piecewise Functions. International Journal of Computer Integrated Manufacturing, 21(4), pp: 353-365.

Araz C. and Ozkarahan I., 2007. Supplier evaluation and management system for strategic sourcing based on a new multicriteria sorting procedure. Int. J. Production Economics 106, pp: 585-606.

Barbarosoglu G. and Yazgac T., 1997. An application of Analytical Hierarchy Process to supplier selection problem. Production and inventory management journal, First quarter, pp: 14-21.

Barzilai J., Cook W.D. and Golany B., 1987. Consistent Weights for Judgements Matrices of the Relative Importance of Alternatives. Operations Research Letters 6 (1), pp: 131134.

Benyoucef L. and Ding H., 2003. Supplier selection problem: selection criteria and methods, INRIA Research report $\mathrm{N}^{\circ} 4726$.

Bidault F., Butler C. and Despres C., 1998. The Drivers of Cooperation between Buyers and Suppliers for Product Innovation. Research Policy, 26, № 7/8, pp: 719-73.

Budescu D.V., Zwick R. and Rapoport A., 1986. A Comparison of the Eigenvalue Method and the Geometric Mean Procedure for Ratio Scaling. Applied Psychological Measurement 10 (1), pp: 69-78.

Cartwright D, 1959. A Field Theoretical Conception of Power. Studies in Social Power, Dorwin Cartwright (ed.), Ann Arbor, University of Michigan Press.

Cho D. and Chu W., 1994. Determinants of bargaining power in OEM negotiations. Industrial Marketing Management, 23, pp: 343-355.

Chung S., Singh H. and Lee K., 2000. Complementarily, status similarity and social capital as drivers of alliance formation. Strategic Management Journal, 21(1), pp: 1-22.

Clark K.B. and Fujimoto T., 1991. Product development performance: strategy, prganisation and management in the world of Auto Industry. Harvard business school press, Boston, MA.

Crook T.R., James A.L. and Combs G., 2007. Sources and consequences of bargaining power in supply chains. Journal of Operations Management 25, pp: 546-555. 
Croom S.R, 2000. The dyadic capabilities concept: examining the processes of key supplier involvement in collaborative product development. European Journal of Purchasing \& Supply Management, 7(1), pp: 29-37.

Cusumano M.A. and Takeishi A., 1991. Supplier Relations and Management: A Survey of Japanese, Japanese-Transplant, and U.S. Auto Plants. Strategic Management Journal, 12 (8), pp: 563-588.

Derrouiche R., Neubert G. and Bouras A., 2007. Supply Chain Management : A framework to characterize the Collaborative Strategies. International Journal of Computer Integrated Manufacturing, 21(4), pp: $426-439$.

Dickson G.W., 1996. An analysis of vendor selection: systems and decisions. Journal of purchasing, 1 (2), pp: 5-17.

Dowlatshahi S., 1998. Implementing early supplier involvement: a conceptual framework. International journal of operations and production management, 18(2), pp: 143-167.

Eisenhardt K.M. and Tabrizi B.N., 1995. Accelerting adaptative processes: product innovation in the global computer industry. Administrative science quaterly, 40, pp: 84110.

Emerson R.M., 1962. Power-dependence relations. American Sociological Review, 27, pp: 47-52.

Emden Z., Calantone R.J. and Droge C., 2006. Collaborating for new product development: selecting the partner with maximum potential to create value. Journal of Product Innovation Management, 23 (4), pp: 330-341.

Feng B., Fan Z.P. and Mac J., 2000. A method for partner selection of codevelopment alliances using individual and collaborative utilities. Int. J. Production Economics, 124, pp: $159-170$.

Flynn B., Zhao X., Huo B. and Yeung J.H.Y., 2008. We've got the power! How customer power affects supply chain relationships, Business Horizons, 51, pp: 169-174.

Gaski J.F., 1984. The theory of power and conflict in channels of distribution. Journal of marketing, 48, pp: 9-29.

Geringer J.M., 1991. Strategic determinants of partner selection criteria in International joint ventures, Journal of International Business Studies, 22(1), pp: 41-61.

Golany B. and Kress M., 1993. A Multicriteria Evaluation of the Methods for Obtaining Weights from Ratio-Scale Matrices. European Journal of Operational Research, 69, pp: 210-202. 
Hartley J.L. and Jones G.E., 1997. Process Oriented Supplier Development: Building the Capability for Change. Journal of Supply Chain Management 33 (3), pp: 24-29.

Hartley J.L., Zirger B.J., and Kamath R.R., 1997. Managing buyer-supplier interface for ontime performance in product development. Journal of operations management,15, pp: 57-70.

Heide J.B. and John G., 1990. Alliances in Industrial Purchasing: The Determinants of Joint Action in Buyer-Supplier Relation- ships. Journal of Marketing Research, 27, pp: 24-36.

Hitt M.A., Dacin M.T., Levitas E., Arregle J.L., and Borza A., 2000. Partner selection in emerging and developed market contexts: Resource-based and organizational learning perspectives. Academy of Management Journal, 43(3), pp: 449-467.

Huang G.Q., Mak K.L. and Humphereys P.K., 2003. A new model of the customer-supplier partnership in new product development. Journal of Materials Processing Technology, 138 (1), pp. 301-305.

Huang S.H. and Keskar H., 2007. Comprehensive and configurable metrics for supplier selection. Int. J of Production Economics, 105, pp: 510-523.

Huang G.Q., and Mak K. L., 2001. Issues in the development and implementation of web applications for product design and manufacture. International Journal of Computer Integrated Manufacturing, 14(1), pp:125-135

Imai K.I., Nonaka H. and Takeuchi H, 1986. Managing the new roduct development: How Japanese companies learn and unlearn. In K.B.Clarke and C.Lorenz (Eds.), The uneasy alliance. Boston, Harvard business school press.

Johnsen Th.E., 2009. Supplier involvement in new product development and innovation: taking stock and looking to the future. Journal of Purchasing and Supply Management, 15(3), pp: 187-197.

Kalwanin M.U. and Narayandas N., 1995. Long-term manufacturer-supplier relationships: do they pay off for supplier firms. Journal of marketing, 59, pp: 1-16.

Kamath R.R. and Liker J.K., 1994. A Second Look at Japanese Product Development, Harvard Business Review, 72, pp: 154-170.

Koufteros X. A., Cheng T.C.E. and Lai K.H., 2007. "Black-box" and "gray-box" supplier integration in product development: Antecedents, consequences and the moderating role of firm size. Journal of Operations Management, 59, pp:847-870.

LaBahn D.W. and Krapfel R., 2000. Early supplier involvement in customer new product development: a contingency model of component supplier intentions. Journal of business research, 47, pp: 173-190. 
Lambert D.M., Emmelhainz M.A. and Gardner J.T., 1996. Supply Chain Partnership: Model validation and Implementation. Journal of business Logistics, 25(2), pp: 21- 42.

Lamming R., 1993. Beyond Partnership: Strategies for Innovation and Lean Supply, Prentice-Hall, Hemel Hempstead.

Lau C., Henry W. and Wong T.T., 2002. Partner Selection and Information Infrastructure of a Virtual Enterprise Network. International Journal of Computer Integrated Manufacturing, 14(2), pp: 186-193.

Lawler E.J., 1992. Power Processes in Bargaining. The Sociological Quarterly, 33(1), pp: 17-34.

Liker J., 2003. The Toyota Way, McGraw-Hill.

Martin R., 1992. Bargaining Power. Clarendon Press Oxford.

McAlister L., Baxerman M.H. and Fader P., 1986. Power and Goal Setting in Channel Negotiations. Journal of Marketing Research 23, pp: 228-236.

Nidamarthi S., Allen R. H., and Sriram R. D., 2001. Observations from supplementing the traditional design process via Internet-based collaboration tools. International Journal of Computer Integrated Manufacturing, 14(1), pp:95-107.

Nishigushi T., 1994. Strategic industrial sourcing: the Japanese advantage. Oxford. Oxford University Press.

Pertersen K.J., Handfield R.B. and Ragatz G.L., 2005. Supplier integration into new product development: coordinating product process and supply chain design. Journal of operations management, 23 (3-4), pp: 371-388.

Pfeffer J. and Salancik G.R., 1978. The external control of organizations, Library of Congress Cataloging in Publication Data.

Porter M.E., 1980. Competitive Strategy: Techniques for Analyzing Industries and Competitors, Free Press.

Pruitt D.G., 1981. Negotiation Behavior, Academic Press, New York.

Primo A.M. and Amundson S.D., 2002. An exploratory study of effects of supplier relationships on new product development outcomes, Journal of operations management, 20 (1), pp: 33-52.

Ragatz G.L, Handfield R.B. and Petersen K.J., 2002. Benefits associated with supplier integration into new product development under conditions of technological uncertainty. Journal of Business Research, 55, pp: 389-400.

Rothwell R., 1974. SAPPHO updated-project SAPPHO phase 2. Research Policy, 3, pp: 258-291. 
Saaty T.L., 2005. Theory and applications of the Analytic Network Processes. RWS Publications.

Sanchez-Rodriguez C., Hemsworth D. and Martinez-Lorente A.R., 1996. The effect of supplier development initiatives on purchasing performance: a structural model. Supply Chain Management, 10 (4), pp: 289 - 301.

Shore B. and Venkatachalam A.R., 2000. Evaluating the information sharing capabilities of supply chain partners: A fuzzy logic model. International Journal of Physical Distribution \& Logistics Management, 33(9), pp: 804 - 824.

Slade B.N., 1993. Compressing the product development cycle : from research to marketplace. Amacom, Amercian management association, New York, NY.

Song M. and Beneditto A.D., 2008. Supplier's involvement and success of radical new product development in new ventures. Journal of operations management, 26 (1), pp: 122.

Swink M.L., 1999. Threats to new product manufacturability and the effects of development team integration process. Journal of operations management, 17, pp: 691709.

Tenbrunsel A.E., Wade-Benzoni K.A., Moag J. and Bazerman M.H, 1997. The Negotiation Matching Process: Relationships and Partner Selection, Organizational Behavior and Human Decision Processes, 80 (3), pp: 252-283.

Ulrich K.T. and Eppinger S.D., 2003. Product design and development. McGraw Hill.

Van Echtelt F.E.A., Wynstra F., Van Weele A.J. and Duysters G, 2008. Managing Supplier Involvement in New Product Development: A Multiple-Case Study, Journal of Production Innovation Management, 25, pp: 180-201.

Bertalanffy L.V., 1976. General System Theory: Foundations, Development, George Braziller; Revised edition.

Wasti S.N. and Lieker J.K., 1997. Risky business or competitive power? Supplier involvement in Japanese product design. Journal of product innovation management, 14, pp. 337-355.

Weber C.A., Current J.R. and Benton W.C., 1991. Vendor selection criteria and methods. European Journal of Operational Research, 50, pp: 2-18.

Womack J.P., Jones D.T. and Roos D., 1991. The machine that change the world, Harper Perennial edition.

Wu D., Baron O. and Berman 0., 2009. Bargaining in competing supply chains with uncertainty. European Journal of Operational Research, 197, pp: 548-556. 
Zhao X.H., Flynn B.B. and Yeung J.H.Y., 2008. The impact of power and relationship commitment on the integration between manufacturers and customers in a supply chain. Journal of Operations Management, 26, pp: 368-388. 

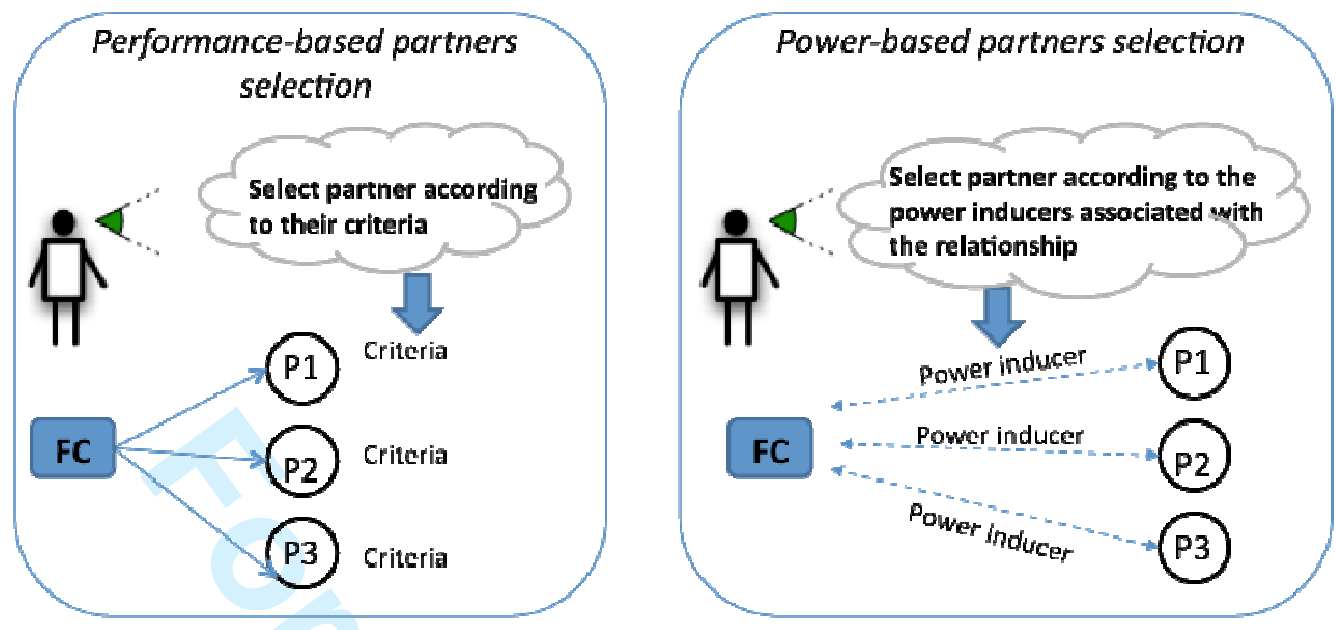

Figure1. Performance-based partner selection vs. power-based partner selection

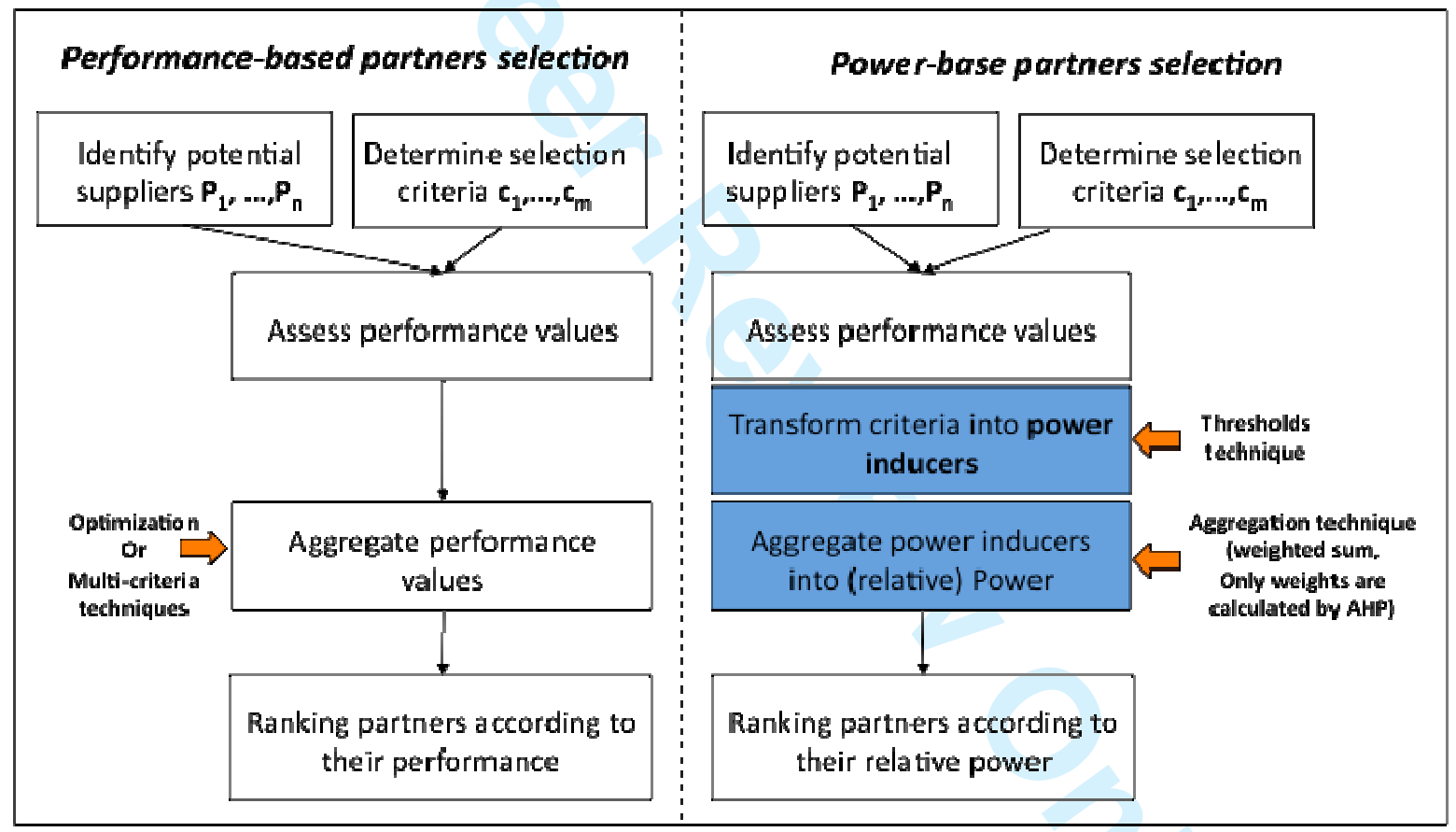

Figure.2 - Power-based and performance-based partner selection approaches 
Example 1: Published delivery cycle time

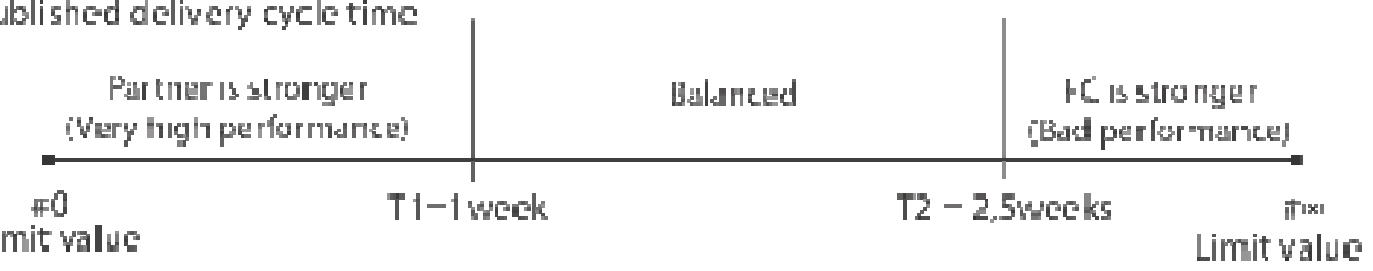

Example 2.Fill rate

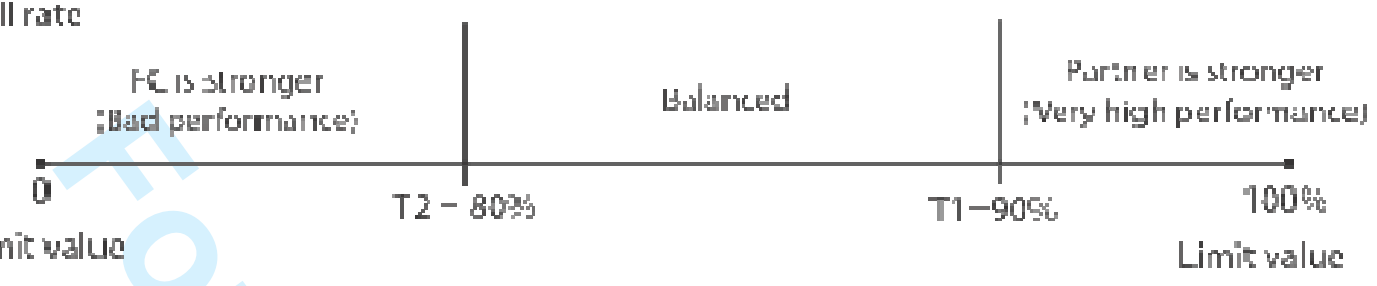

Figure 3 - Threshold technique

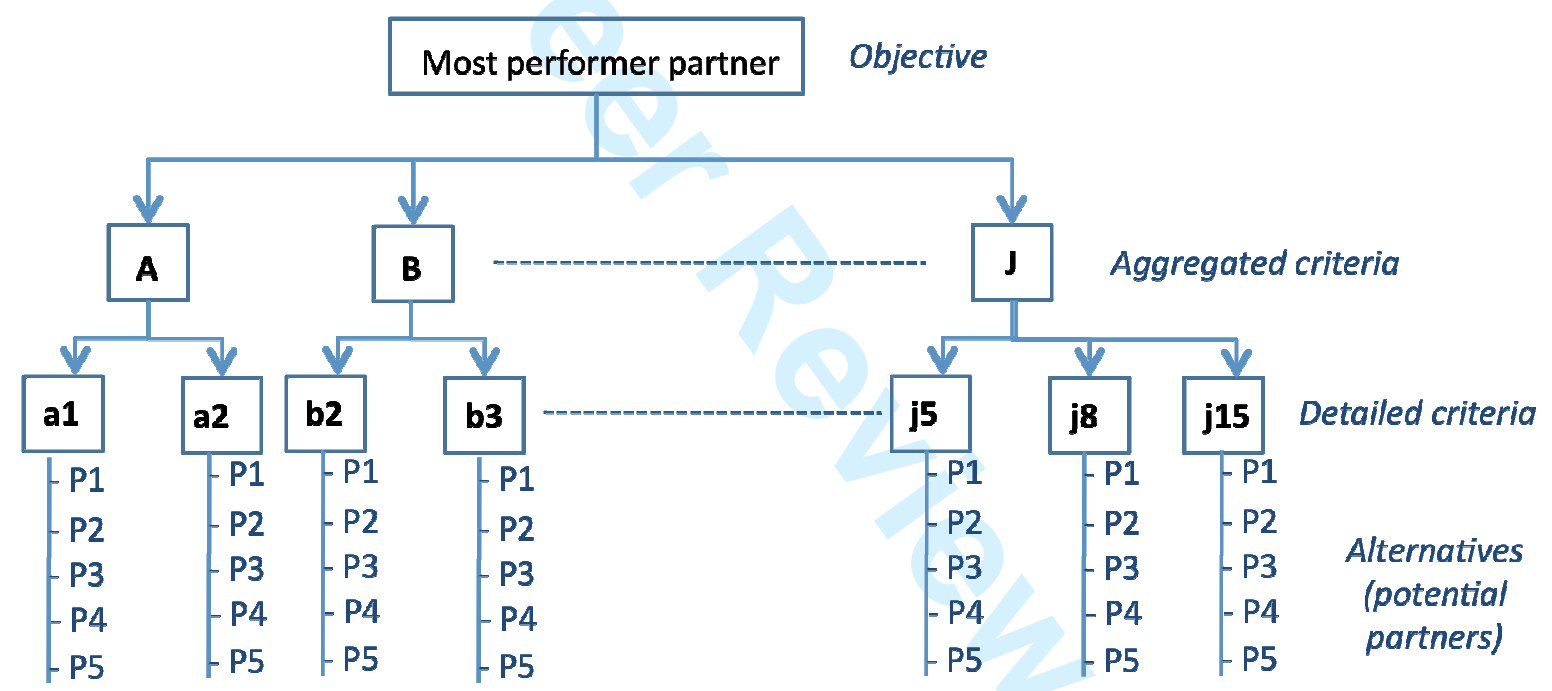

Figure 4: The performance-based partners selection approach using the AHP technique 


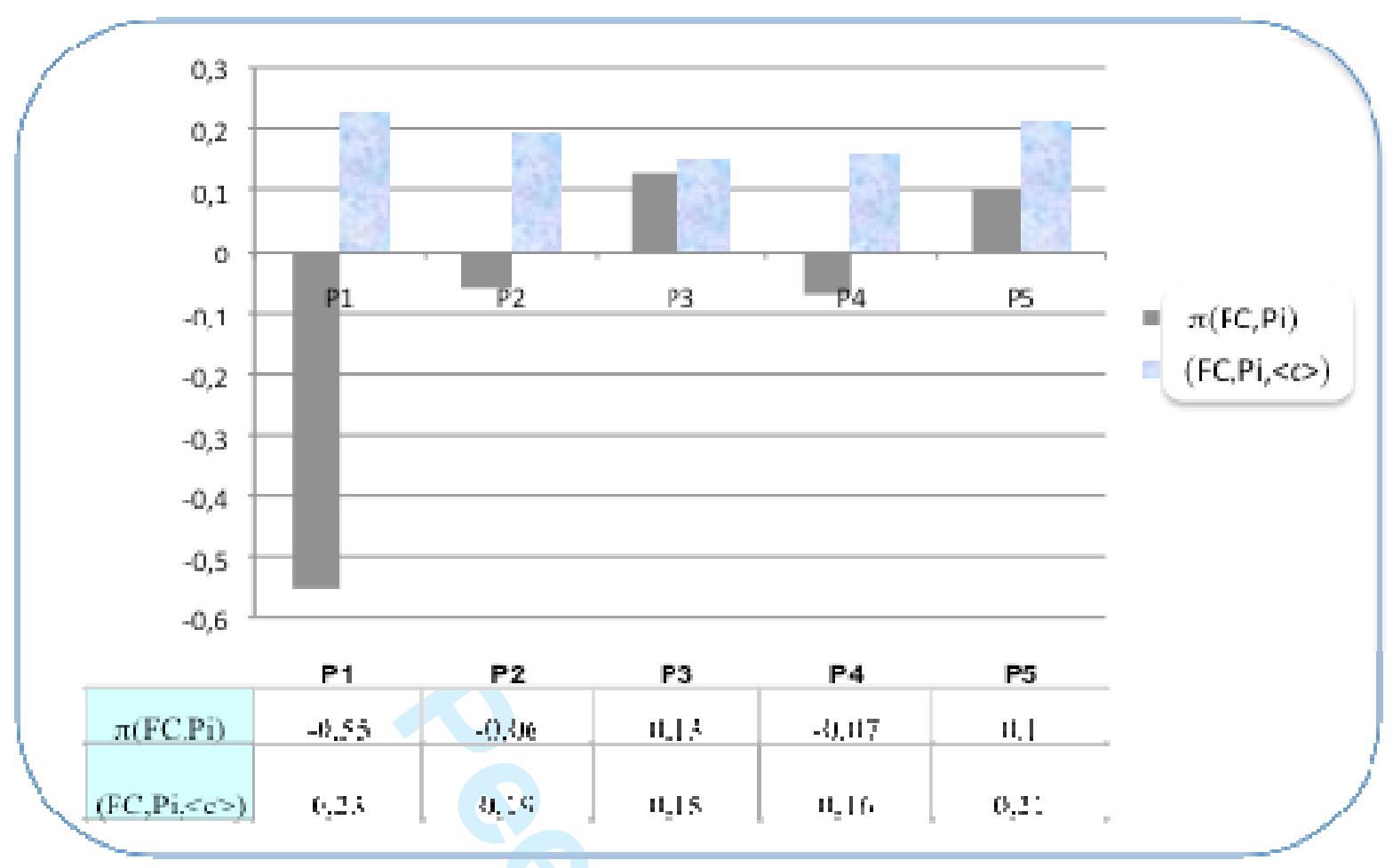

Figure 5 - Profiles of performance values and power values 


\begin{tabular}{|c|c|c|c|}
\hline \multicolumn{2}{|c|}{ Supplier's point of view } & \multicolumn{2}{|c|}{ Customer's point of view } \\
\hline Potential benefits & Potential risks & Potential benefits & $\begin{array}{l}\text { No benefits or } \\
\text { Potential risks }\end{array}$ \\
\hline $\begin{array}{l}\text { Support (technical, } \\
\text { organisational, ...) of } \\
\text { the customer. } \\
\text { (Nishigushi, 1994) }\end{array}$ & $\begin{array}{l}\text { Price rollbacks, } \\
\text { abrogating supply } \\
\text { agreements } \\
\text { (LaBahn,2000) }\end{array}$ & $\begin{array}{l}\text { Successful innovation } \\
\text { (Rothwell et al., 1974, } \\
\text { DeBreson and Amesse, 1991, } \\
\text { Womack et al. 1991, Imai, } \\
\text { 1986, Clark and Fujimoto, } \\
\text { 1991) }\end{array}$ & $\begin{array}{l}\text { Technologically less } \\
\text { predicitble projects } \\
\text { (Eisenhardt and } \\
\text { Tabrizi, 1995) }\end{array}$ \\
\hline $\begin{array}{l}\text { Technology transfer } \\
\text { (Nishigushi, 1994) }\end{array}$ & $\begin{array}{l}\text { Uncovered } \\
\text { investments for } \\
\text { ESI. } \\
\text { (LaBahn,2000) }\end{array}$ & $\begin{array}{l}\text { Better use of suppliers' } \\
\text { technological competence } \\
\text { (Slade, 1993) }\end{array}$ & $\begin{array}{l}\text { No significant benefit } \\
\text { (Eisenhardt and } \\
\text { Tabirzi, 1995) }\end{array}$ \\
\hline \multirow[t]{2}{*}{$\begin{array}{l}\text { Reducing costs, } \\
\text { reduce } \\
\text { administrative, } \\
\text { selling and overheads } \\
\text { costs (Kalwani and } \\
\text { Narayandas, } 1995\end{array}$} & $\begin{array}{l}\text { Customer } \\
\text { appropriating of } \\
\text { supplier's } \\
\text { technology } \\
\text { (LaBahn, 2000) }\end{array}$ & $\begin{array}{l}\text { Higher performances: } \\
\text { Reduced costs and time to } \\
\text { market and improved quality } \\
\text { and productivity, speed } \\
\text { (Womack et al. 1991, Imai, } \\
\text { 1986, clark and fujimoto, } \\
\text { 1991, kamath and Lieker } \\
\text { 1994, Ragatz et al., 2002, } \\
\text { Song aned Beneditto, 2008) } \\
\text { Improved design for } \\
\text { manufacturing } \\
\text { (Wasti and Liker, 1997, }\end{array}$ & $\begin{array}{l}\text { No reduction in time- } \\
\text { to-market (Hartley et } \\
\text { al, 1997) }\end{array}$ \\
\hline & & $\begin{array}{l}\text { Decreasing risk of design- } \\
\text { related delay (Hartley et al, } \\
\text { 1997) }\end{array}$ & \\
\hline
\end{tabular}

Table1. Benefits and risks of ESI

\begin{tabular}{lc}
\hline Judgement or verbal preference & Numerical assessment \\
\hline Extreme importance & 9 \\
Very strong or demonstrated importance & 7 \\
Strong importance & 5 \\
Moderate importance & 3 \\
Equal importance & 1 \\
Intermediate values (to be used if trade-offs are required) & $2,4,6$ and 8 \\
\hline
\end{tabular}

Table 2 - Preference scale used in the AHP method 


\begin{tabular}{|c|c|c|c|c|c|c|c|c|c|c|c|c|c|c|}
\hline & Critieria & Domain & P1 & P2 & P3 & P4 & P5 & T1 & T2 & P1 & P2 & P3 & P4 & P5 \\
\hline a1 & Net price $(\epsilon)$ & Real & 35 & 50 & 45 & 70 & 100 & 40 & 80 & -1 & 0 & 0 & 0 & 1 \\
\hline a3 & $\begin{array}{l}\text { Position regarding the price } \\
\text { within the sector }\end{array}$ & (VB,B,A,G,VG) & VG & A & B & B & G & A & VG & -1 & 0 & 1 & 1 & 0 \\
\hline b2 & Design delay (days) & Real & 60 & 120 & 100 & 45 & 70 & 30 & 50 & 1 & 1 & 1 & 0 & 1 \\
\hline b3 & RFQ delay (days) & Real & 15 & 10 & 15 & 5 & 25 & 7 & 12 & 1 & 0 & 1 & -1 & 1 \\
\hline c2 & Target policy quality & $(\mathrm{Y}, \mathrm{N})$ & Y & Y & $\mathrm{Y}$ & $\mathrm{Y}$ & $\mathrm{Y}$ & $\mathrm{Y}$ & $\mathrm{N}$ & -1 & -1 & -1 & -1 & -1 \\
\hline c9 & Process control & $(\mathrm{Y}, \mathrm{N})$ & Y & $\mathrm{N}$ & $\mathrm{N}$ & $\mathrm{N}$ & $\mathrm{Y}$ & $\mathrm{Y}$ & $\mathrm{N}$ & -1 & 1 & 1 & 1 & -1 \\
\hline d2 & Job definition & (VB,B,A,G,VG) & VG & VG & B & G & B & A & VG & -1 & -1 & 1 & 0 & 1 \\
\hline d4 & Management and organisation & $(\mathrm{VB}, \mathrm{B}, \mathrm{A}, \mathrm{G}, \mathrm{VG})$ & VG & G & G & VG & VG & A & VG & -1 & 0 & 0 & -1 & -1 \\
\hline e1 & After-sale service & $(\mathrm{Y}, \mathrm{N})$ & Y & Y & $\mathrm{Y}$ & $\mathrm{Y}$ & $\mathrm{Y}$ & $\mathrm{Y}$ & $\mathrm{N}$ & -1 & -1 & -1 & -1 & -1 \\
\hline e2 & Warranty and claim policy & $(\mathrm{VB}, \mathrm{B}, \mathrm{A}, \mathrm{G}, \mathrm{VG})$ & B & G & B & VG & B & B & G & 0 & -1 & 0 & 1 & 0 \\
\hline e3 & Training and assistance & $(\mathrm{Y}, \mathrm{N})$ & $\mathrm{N}$ & Y & N & $\mathrm{N}$ & N & $\mathrm{r}$ & $\mathrm{N}$ & 1 & -1 & 1 & 1 & 1 \\
\hline f1 & $\begin{array}{l}\text { Design force (designers, tools, } \\
\text { etc...) }\end{array}$ & $(\mathrm{VB}, \mathrm{B}, \mathrm{A}, \mathrm{G}, \mathrm{VG})$ & VG & G & G & G & G & A & VG & -1 & 0 & 0 & 0 & 0 \\
\hline $\mathrm{f} 2$ & $\begin{array}{l}\text { Co-operation attitude and } \\
\text { engagement }\end{array}$ & (VB,B,A,G,VG) & A & A & G & B & VG & A & VG & 0 & 0 & 0 & 1 & -1 \\
\hline g1 & Design tasks management & $(\mathrm{VB}, \mathrm{B}, \mathrm{A}, \mathrm{G}, \mathrm{VG})$ & VG & G & VG & G & A & B & G & -1 & 0 & -1 & 0 & 0 \\
\hline g3 & $\begin{array}{l}\text { Design process improvement } \\
\text { policy }\end{array}$ & $(\mathrm{Y}, \mathrm{N})$ & Y & Y & N & $\mathrm{Y}$ & N & $\gamma$ & N & -1 & -1 & 1 & -1 & 1 \\
\hline h5 & Manufacturing planning system & $(\mathrm{Y}, \mathrm{N})$ & Y & Y & Y & $\mathrm{Y}$ & $\mathrm{Y}$ & $\mathrm{Y}$ & $\mathrm{N}$ & -1 & -1 & -1 & -1 & -1 \\
\hline h8 & $\begin{array}{l}\text { Facility's efficiency regarding } \\
\text { internal logistics }\end{array}$ & (VB,B,A,G,VG) & VG & B & B & G & G & A & VG & -1 & 1 & 1 & 0 & 0 \\
\hline$i 4$ & $\begin{array}{l}\text { Inspection and quality tests on in- } \\
\text { process items }\end{array}$ & $(\mathrm{VB}, \mathrm{B}, \mathrm{A}, \mathrm{G}, \mathrm{VG})$ & G & G & G & G & VG & A & VG & 0 & 0 & 0 & 0 & 1 \\
\hline 15 & $\begin{array}{l}\text { Inspection and quality tests on } \\
\text { final products }\end{array}$ & (VB,B,A,G,VG) & G & G & G & G & G & B & G & 0 & 0 & 0 & 0 & 0 \\
\hline$j 5$ & Brand image & (VB,B,A,G,VG) & VG & VG & A & A & A & B & G & -1 & -1 & 0 & 0 & 0 \\
\hline j8 & Geographical distance & Real & 800 & 6000 & 300 & 2000 & 2000 & 3000 & 5000 & -1 & 1 & -1 & -1 & -1 \\
\hline j15 & $\begin{array}{l}\text { Position of the potential partner } \\
\text { within the sector }\end{array}$ & $(\mathrm{VB}, \mathrm{B}, \mathrm{A}, \mathrm{G}, \mathrm{VG})$ & G & A & A & A & A & A & VG & 0 & 0 & 0 & 0 & 0 \\
\hline
\end{tabular}

Table 3 - Used performance metrics, suppliers, thresholds and power inducers

\begin{tabular}{|c|c|c|c|c|c|c|c|c|}
\hline \multicolumn{2}{|c|}{$\beta \mathbf{i}$} & \multicolumn{6}{|c|}{$\alpha \mathbf{i j}$} & \multirow{2}{*}{$\frac{\sum \alpha i j}{=1}$} \\
\hline $\mathbf{A}$ & 0,214 & a1 & 0,875 & a3 & 0,125 & \multirow{9}{*}{ e3 } & \multirow{9}{*}{0,143} & \\
\hline B & 0,148 & b2 & 0,857 & b3 & 0,143 & & & $=1$ \\
\hline C & 0,199 & c2 & 0,5 & c9 & 0,5 & & & $=1$ \\
\hline D & 0,045 & $\mathrm{~d} 2$ & 0,5 & $\mathrm{~d} 4$ & 0,5 & & & $=1$ \\
\hline $\mathbf{E}$ & 0,08 & e1 & 0,429 & e2 & 0,429 & & & $=1$ \\
\hline $\mathbf{F}$ & 0,072 & f1 & 0,75 & f2 & 0,25 & & & $=1$ \\
\hline G & 0,071 & g1 & 0,5 & g3 & 0,5 & & & $=1$ \\
\hline $\mathbf{H}$ & 0,056 & h5 & 0,8 & h8 & 0,2 & & & $=1$ \\
\hline I & 0,06 & i4 & 0,333 & i5 & 0,667 & & & $=1$ \\
\hline $\mathrm{J}$ & 0,056 & j5 & 0,458 & j8 & 0,126 & j15 & 0,416 & $=1$ \\
\hline$\Sigma \beta \mathrm{i}$ & $=1$ & & & & & & & \\
\hline
\end{tabular}

Table 4 - Weights of detailed and aggregated criteria

\section{Appendix}


Weights [obtained bV geometric means]

Weights bij (obtained by peometric means)

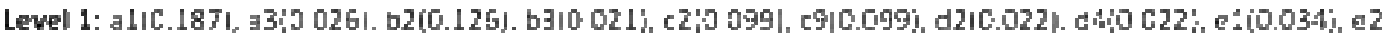

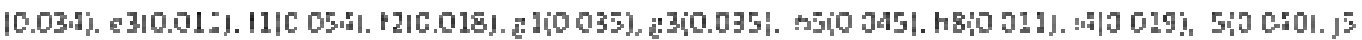

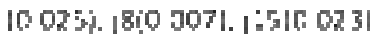

Weights gi ('obtained by geometric means)

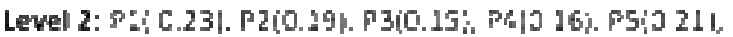

\begin{tabular}{|c|c|}
\hline \multicolumn{2}{|c|}{ Partners' ranking regarding every detailed criterion } \\
\hline a1/ & $\mathrm{P} 1(0.11), \mathrm{P} 2(0.16), \mathrm{P} 3(0.15), \mathrm{P} 4(0.23), \mathrm{P} 5(0.33)$, \\
\hline $\mathrm{a} 3 /$ & $\mathrm{P} 1(0.42), \mathrm{P} 2(0.16), \mathrm{P} 3(0.06), \mathrm{P} 4(0.05), \mathrm{P} 5(0.29)$, \\
\hline b2/ & $\mathrm{P} 1(0.15), \mathrm{P} 2(0.30), \mathrm{P} 3(0.25), \mathrm{P} 4(0.11), \mathrm{P} 5(0.17)$, \\
\hline b3/ & $\mathrm{P} 1(0.05), \mathrm{P} 2(0.03), \mathrm{P} 3(0.05), \mathrm{P} 4(0.01), \mathrm{P} 5(0.08)$, \\
\hline$c 2 /$ & $\mathrm{P} 1(0.2), \mathrm{P} 2(0.2), \mathrm{P} 3(0.06), \mathrm{P} 4(0.2), \mathrm{P} 5(0.2)$ \\
\hline c9/ & $\mathrm{P} 1(0.44), \mathrm{P} 2(0.08), \mathrm{P} 3(0.06), \mathrm{P} 4(0.04), \mathrm{P} 5(0.36)$, \\
\hline $\mathrm{d} 2 /$ & $\mathrm{P} 1(0.37), \mathrm{P} 2(0.37), \mathrm{P} 3(0.05), \mathrm{P} 4(0.14), \mathrm{P} 5(0.04)$, \\
\hline d4/ & $\mathrm{P} 1(0.28), \mathrm{P} 2(0.09), \mathrm{P} 3(0.09), \mathrm{P} 4(0.23), \mathrm{P} 5(0.28)$ \\
\hline e1/ & $\mathrm{P} 1(0.2), \mathrm{P} 2(0.2), \mathrm{P} 3(0.06), \mathrm{P} 4(0.2), \mathrm{P} 5(0.2)$ \\
\hline $\mathrm{e} 2 /$ & $\mathrm{P} 1(0.08), \mathrm{P} 2(0.29), \mathrm{P} 3(0.08), \mathrm{P} 4(0.47), \mathrm{P} 5(0.06)$ \\
\hline $\mathrm{e} 3 /$ & $\mathrm{P} 1(0.14), \mathrm{P} 2(0.48), \mathrm{P} 3(0.11), \mathrm{P} 4(0.13), \mathrm{P} 5(0.11)$, \\
\hline f1/ & $\mathrm{P} 1(0.43), \mathrm{P} 2(0.14), \mathrm{P} 3(0.14), \mathrm{P} 4(0.14), \mathrm{P} 5(0.14)$. \\
\hline f2/ & $\mathrm{P} 1(0.16), \mathrm{P} 2(0.16), \mathrm{P} 3(0.24), \mathrm{P} 4(0.05), \mathrm{P} 5(0.38)$, \\
\hline g1/ & $\mathrm{P} 1(0.34), \mathrm{P} 2(0.13), \mathrm{P} 3(0.34), \mathrm{P} 4(0.13), \mathrm{P} 5(0.05)$, \\
\hline $\mathrm{g} 3 /$ & $\mathrm{P} 1(0.30), \mathrm{P} 2(0.30), \mathrm{P} 3(0.07), \mathrm{P} 4(0.25), \mathrm{P} 5(0.06)$ \\
\hline h5/ & $\mathrm{P} 1(0.2), \mathrm{P} 2(0.2), \mathrm{P} 3(0.06), \mathrm{P} 4(0.2), \mathrm{P} 5(0.2)$ \\
\hline h8/ & $\mathrm{P} 1(0.54), \mathrm{P} 2(0.08), \mathrm{P} 3(0.08), \mathrm{P} 4(0.11), \mathrm{P} 5(0.17)$, \\
\hline i4/ & $\mathrm{P} 1(0.14), \mathrm{P} 2(0.14), \mathrm{P} 3(0.14), \mathrm{P} 4(0.14), \mathrm{P} 5(0.43)$, \\
\hline$i 5 /$ & $\mathrm{P} 1(0.2), \mathrm{P} 2(0.2), \mathrm{P} 3(0.06), \mathrm{P} 4(0.2), \mathrm{P} 5(0.2)$ \\
\hline $\mathrm{j} 5 /$ & $\mathrm{P} 1(0.38), \mathrm{P} 2(0.38), \mathrm{P} 3(0.08), \mathrm{P} 4(0.08), \mathrm{P} 5(0.08)$, \\
\hline j8/ & $\mathrm{P} 1(0.07), \mathrm{P} 2(0.54), \mathrm{P} 3(0.02), \mathrm{P} 4(0.18), \mathrm{P} 5(0.18)$. \\
\hline j15/ & $\mathrm{P} 1(0.35), \mathrm{P} 2(0.11), \mathrm{P} 3(0.11), \mathrm{P} 4(0.11), \mathrm{P} 5(0.18)$, \\
\hline
\end{tabular}

